TESSITURAS ENTRE IMAGEM E A IMAGINAÇÃO DO REAL

WEAVES BETWEEN IMAGES AND IMAGINATION OF THE REAL

Angela Grando

PPGA-UFES

Resumo: No âmbito desta comunicação abordamos as relações geradas no jogo de imagens que se estabelecem e dão sentido as obras Je est un autre e Sal sem carne, de Cildo Meireles. E, pela aproximação esclarecedora que aporta a filosofia de Henri Bergson, busca-se discutir como o conceito bergosiano de "imagem" contribui de um modo peculiar à eventual interpretação entre novas situações de consciencialização do espectador e o índice conceitual da obra que atesta e problematiza o discurso social em arte.

Palavras-chave: Cildo Meireles, imagem, arte e vida.

Abstract: In the scope of this communication we approach the relations generated in the game of images that are established and give meaning to the works Je est un autre and Salt without meat, by Cildo Meireles. And, by the enlightening approach of Henri Bergson's philosophy, willing to discuss how the Bergensian concept of "image" contributes in a peculiar way to the possible interpretation between new situations of awareness of the spectator and the conceptual index of the work that attests and problematizes the social discourse in art.

Keywords: Cildo Meireles, image, art and life. 
Figura 2. Cildo Meireles, Je est un autre (detalhe-1997), Instalação, 2 projeções de vídeo filmadas ao vivo do circuito da água de rio que passa pelos $1.000 \mathrm{~m}$ de tubos transparentes. Centro de arte contemporânea Le Creux de l'Enfer,

Thiers, France. Fonte: http://www.creuxdelenfer.net

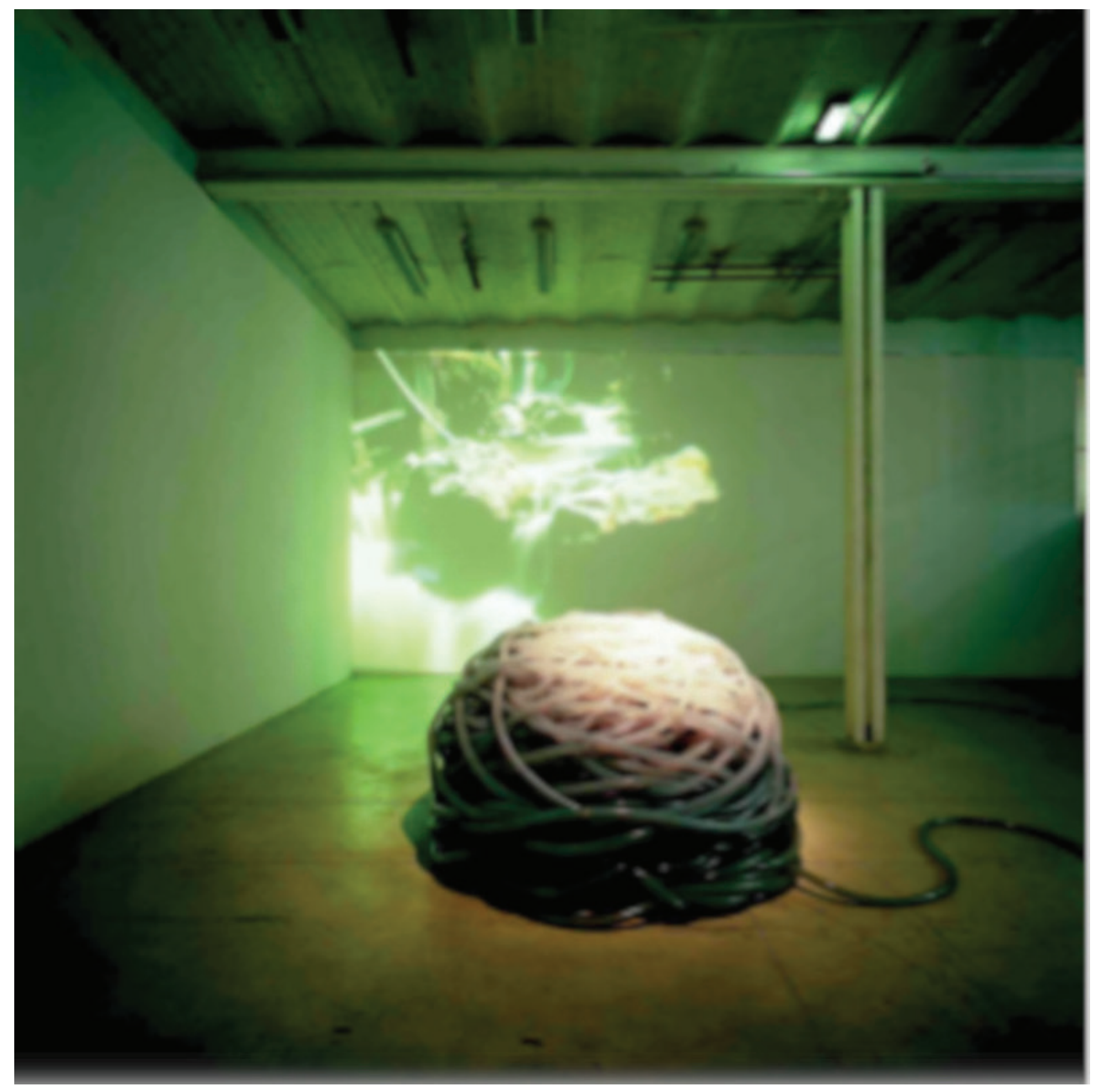

lismo industrial, "que é crescer, crescer, crescer, o que quer dizer que ele se funda no princípio da infinitude. Ele diz: "o planeta terra é grande mas ele não é infinito [...] sei que daqui a 20 anos no mínimo 90\% do planeta terra vai estar enfrentando o problema de água potável" (Meireles, 2013). É neste contexto que Je est un autre parece repousar sobre alguma espécie impossível de equilíbrio, e, por assim dizer, na tensão induzida por Rimbaud à necessidade de "changer la vie".

O que se passa é que essa instalação flui, em meio a tantas nuanças expressivas, no sentido poético de levantar o impasse: o trabalho exige do observador a difícil adesão à falta e ao excesso de significados, mundo e arte misturam-se inextricavelmente na tensão contemporânea de um determinado inconformismo, atrasados em mais de século, aos sintomas de Rimbaud.

Como convém a este texto, optou-se pelo recurso retórico, mas também real, de fazer referência à arte que se manifesta num campo alargado, a partir dos anos 1960, esgarçando as categorias artísticas referenciais da primeira metade do século XX e acentuando o fluxo 
entre arte e vida. Contudo, não custa dizer que se deve ao crescente agrupamento das impressões provocadas pelo mundo fenomenal onde se insere a arte moderna o caminho aberto para novos conceitos de imagem. Desenvolveu-se ali a significativa dimensão do "eu" polissêmico de Rimbaud (Je est un autre), desenvolveu-se ali o sentido da eminência de "imagem" como resultante da ampla rede de relações que a constitui, como propunha, por exemplo, Henri Bergson expressando a percepção concreta complexa, instalando-se sempre em uma espessura de duração. O que implica necessariamente tanto a intervenção da vivência (a experiência do espaço mental que figura na memória, imaginação), como o continuamente presente que seria também continuamente movente (trata-se da experiência imediata, direta) (Bergson, 1975). Essa concepção bergsoniana se sobrepõe à noção desrealizadora de "imagem" pensada em termos de relação exterioridade e interioridade. Sob esse ângulo, uma obra de arte não é a materialização de uma ideia imaterial: a "ideia” em arte é, sobretudo, uma antecipação dos seus efeitos, dos efeitos gerados pelo seu devir "materialidade”. Assim:

A percepção nada mais é, então, do que uma seleção. Ela não cria nada; seu papel é ao contrário, o de eliminar do conjunto de imagens todas aquelas sobre as quais eu não teria qualquer preensão; a seguir, de cada uma das próprias imagens retidas, tudo o que não interessa às necessidades da imagem que chamo de meu corpo. [...] ao colocar meu corpo, coloquei uma certa imagem, mas no mesmo gesto, a totalidade das outras imagens, já que não há objeto material que não deva suas qualidades, suas determinações, sua existência, enfim, ao lugar que ocupa no conjunto do universo (BERGSON, 1975).

Nesse rico contexto, e observando a afirmação segundo a qual a "imagem pode ser sem ser percebida", observe-se que o conceito de "imagem" é eminentemente relacional e, ao mesmo tempo, nem um pouco desmaterializante: ao contrário, propõe Bergson, corresponde à própria materialidade. Mas o filósofo toma o cuidado de alertar que se as relações se dão no âmbito da matéria, e se existe uma rede de relações que a constitui, a matéria não deriva sua determinação do que Ihe viria (supostamente) "de fora".

Daí emerge um aspecto balizar da percepção moderna que vai transitar na operatividade da percepção contemporânea: o "ser relacional", Je est un autre, repotencializado na instalação homônima de Cildo Meireles. Nesta, o artista propõe uma temporalidade que se desenvolve numa dialética porosa entre o suporte visual e a imaginação do real, e lida com um discurso ininterrupto de questões diversas - conceitual, poética, sonora, imagética - que implica em submergir na estreita relação entre identidade e alteridade. Que não se entenda com isto, entretanto, a postulação de um dualismo; mas o reflexo da constante tensão na qual o par arte e vida transita no campo ontologicamente configurado do trabalho de Cildo Meireles.

Nesse sentido, e no eixo conceitual de Bergson que implica o fato de tudo ser relacional, de tudo ser imagem, pontua-se que o processamento de imagens não pulveriza a matéria e que toda matéria e nosso próprio corpo se resumem a imagens. O universo é o conjunto das imagens; o mundo material, um "sistema de imagens solidárias e bem ligadas”. Imagem entre imagens, nosso corpo é um centro de ação. Nossa percepção delineia "precisamente no conjunto de imagens as ações virtuais ou possíveis" da experiência de nosso corpo, facultando-lhe um amplo espectro de possibilidades de ação. 
Figura 3. Cildo Meireles, Foto em preto e branco (detalhe). Fonte: Herkenhoff, Paulo; Mosquera, Gerardo; Cameron, Dan. Cildo Meireles. São Paulo: Cosac \& Naify, p.126.

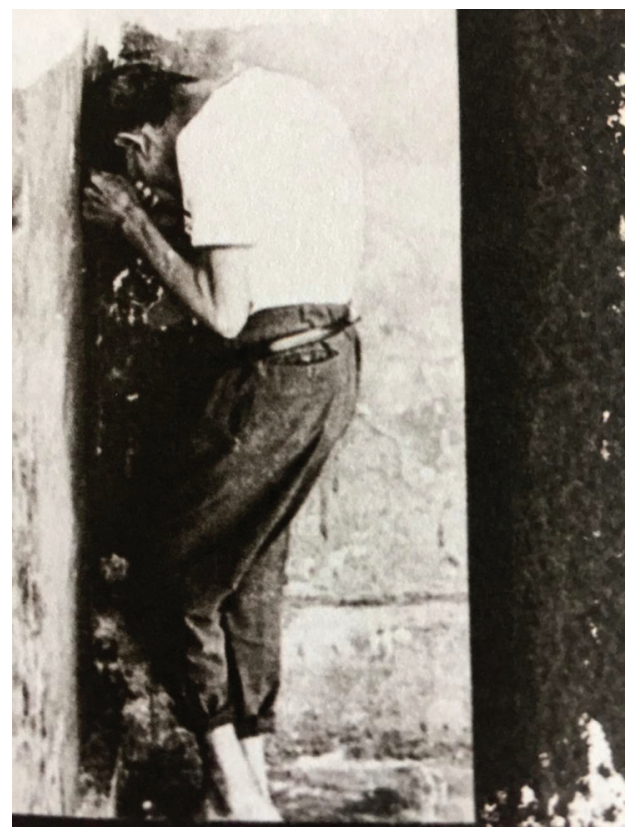

\section{Sal sem carne}

Revela-se que em sua obra Bergson indica a conhecida experiência do déjà vu para atestar uma relação de simultaneidade entre o presente e o vivido. E a rigor, se pensarmos o presente como o instante em que se instalaria nossa experiência, teremos de "admiti-lo como pura ficção". Justamente aqui pensamos encontrar o atalho mais promissor para uma aproximação com a livre apropriação poética de Cildo Meireles, ao apreender uma imagem, em seu anonimato, e leva-la a compor uma peculiar tensão, um estado de ser, em sua obra. É o caso do caráter emblemático de uma mesma imagem fotográfica presente em alguns trabalhos de Cildo Meireles, e sobre a qual ele diz:

Eu tinha feito um trabalho, que era o Sal sem carne, que era um disco, uma radionovela, e por Goiás eu tinha chegado a um hospício, esse hospício mental. Eu não sou fotógrafo, mas fiz uma série de fotos. E quando eu voltei para Brasília, comecei a revelar essas fotos do hospital mental [...] e sempre aparecia lá no fundo um personagem, no mesmo canto
[...] Então eu tinha essa imagem e resolvi usar. [...] são as fotos que eu usei no Zero Cruzeiro e no Sal sem carne [...] (MEIRELES, 2013).

No breve espaço que aqui se impõe, discorro sobre a apreensão dessa fotografia (Figura.3) em Sal sem carne (1975). O processo conceitual da obra, Sal sem carne, traz uma identidade densa de sentidos, suscitando interrogações a respeito de um território em que as tensas relações entre comunidades indígenas e colonizadores se desenrolam, evocando questões ideológicas, restrições étnicas, enfim, "o gueto". Ou seja, uma espécie de "terceiro espaço" resultado de uma cultura híbrida que jamais se concilia.

Tal noção é exemplificada no esforço pela causa indígena na qual o pai de Cildo Meireles trabalhou, e que indignado pelas atrocidades cometidas contra as tribos investigou os vários massacres impostos aos índios diante do poder de destruição de fazendeiros locais. Anos depois, Cildo Meireles foi impedido de entrar no Parque Nacional, criado por seu pai, onde pretendia entrevistar um índio remanescente do massacre. "Com essa restrição, realiza, então, seu trabalho com uma comunidade próxima, uma espécie de "aldeia-rural-periférica-temporária”. Seus entrevistados são, em suas próprias palavras, 'nem brancos, nem índios, mas todos miseráveis'. Para eles, explica Cildo, "eu fazia duas perguntas: Você é um índio? Você sabe o que é um índio? Eles respondiam que o índio comia carne sem sal e essa resposta aparecia como um grande diferenciador" (Grando, 2015).

Com a questão dessa cultura híbrida, o objeto disco Sal sem carne, concentra gravações num LP de 33 rotações, disco de vinil, mixado em oito canais, onde quatro se destinam à cultura portuguesa-branca e quatro à cultura indígena (Figura 4). Uma pluralidade de fotos de pequena dimensão, interligadas em formato de tiras sucessivas de negativos de filme, compõem a visualidade 


\section{AOOOOOO

CM1974
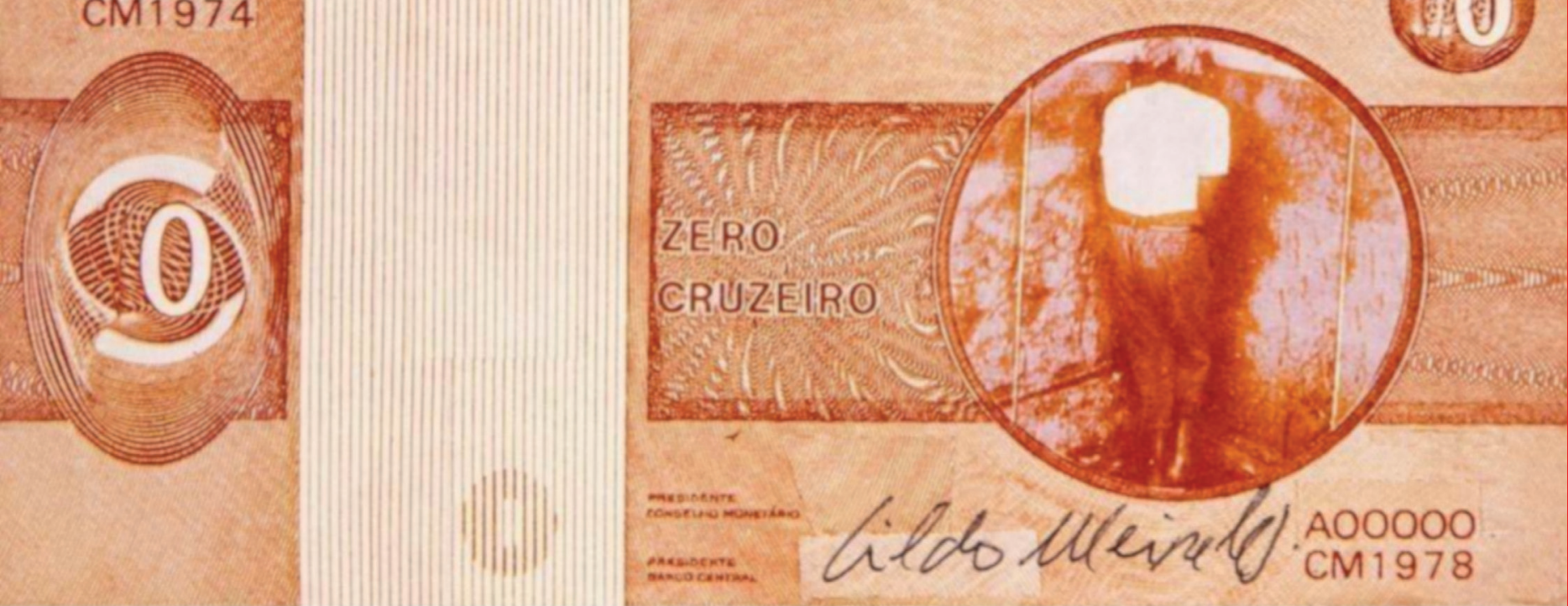

Figura 5. Cildo Meireles, Zero Cruzeiro, 1974-1978, impressão offset s/ papel, $6.5 x$ $15,5 \mathrm{~cm}$. contexto social preciso. Tentativas subjetivas, de explorar imagens do déjà vécu e deslocá-las à temporalidade do vir-a-ser. Espaço topológico, desestabilizador e, portanto, político: passível de envolver o espectador apelando para seus vários sentidos. Exatamente para que reencontre e disponha de uma leitura inteligente, uma experiência estética e reflexiva, solicitada pela arte contemporânea.

\section{Referências}

MEIRELES, Cildo. "Cildo Meireles e o filme 'Ouvir o Rio’. (01 dez. 2013). Disponível em https://www.youtube. com/watch? $v=k$ K82fUNxHpE (Acesso em 05 nov. 2018).

BERGSON, Henri. Matière et vie (textes choisis). Paris: PUF, 1975.

__. Matière et mémoire. In: Oeuvres, t.1.Paris: PUF, 2001.

MEIRELES, Cildo. Entrevista. Revista Carbono, n.4, 2013. ISSN 2358 - 8047. http://revistacarbono.com/artigos/04carbono-entrevista-cildo-meireles/ (consultado em 15 de ago. 2018).

GRANDO, Angela, Sal sem carne - para uma estética do gueto. Artelogie, n 8, Décembre 2015-Janvier 2016. URL: $\quad$ http://journals.openedition.org/artelogie/496; DOl:10.4000/artelogie.496
FREIRE, Cristina. Contexturas: Sobre artistas e/ou antropólogos. Catálogo da Bienal de SP 2015.

\section{Angela Grando}

Doutoradoem HistoriadaArtepela UniversitédeParis| -Sorbonne(2002); Mestrado História daArte pela-Université de Paris I - Sorbonne (1998); Graduação em História da Arte pela Université Paul Valéry - Montpellier III (1985). Professor Titular da UniversidadeFederal do EspíritoSanto, é Bolsista Pesquisador (BPC) da FAPES, coordena o Laboratório de pesquisa em Teorias da Arte e Processos em Artes - UFES/CNPq. Coordenou o Programa de PósGraduação em Artes-PPGA/UFES (ag.2009-fev.2014), coordenou o Programa de Qualificação Institucional - Convênio: PQI-753/2002-CAPES (2002-2007), Foi vice-diretora do Centro deArtes/UFES [1996-1998]. Éeditora da Revista Farol (PPGA-UFES, ISSN 1517-7858); membro do conselho científico da Revista: Estúdio (ISSN1647-6158 e ISSN 16477316, Coordenadora adjunta do PPGA/UFES (2016-). Tem experiência na área de Artes, com ênfase em fundamentos teóricos, história e crítica das artes, atuando principalmentenosseguintestemas: modernismosevanguardas, poéticas da criação na arte moderna e contemporânea, práticas conceituais e participativas em arte contemporânea, novas mídias na arte. 